\title{
Transient Thyrotoxicosis occurred after Cessation of Steroid Therapy in a Patient with Autoimmune Thyroiditis and Rheumatoid Arthritis
}

\author{
Hiroshi MARUYAMA, Masayuki KATO, Osamu MiZUNO, \\ KUNIZO KATAOKA AND SHUN MATSUKI \\ Department of Internal Medicine, Keio University School of \\ Medicine, Tokyo 160, Japan
}

\begin{abstract}
A 51-year-old woman with chronic lymphocytic thyroiditis showed transient thyrotoxicosis at seven weeks after cessation of steroid therapy for treatment of rheumatoid arthritis. Radioactive iodine uptake was only $3 \%$ even in a thyrotoxic state. Aspiration biopsy, performed just before the development of hypothyroidism, revealed histological features compatible with chronic lymphocytic thyroiditis. At two months after the onset of thyrotoxicosis, hypothyroidism developed, and she was kept in a euthyroid state by 1-thyroxine replacement therapy. Irreversible hypothyroidism was comfirmed by the recurrence of hypothyroidism after cessation of thyroid replacement therapy at one year after the onset of thyrotoxicosis. The causal relationship between the cessation of steroid therapy and the occurrence of transient thyrotoxicosis is discussed.
\end{abstract}

It is well documented that patients with subacute thyroiditis have a painful and tender struma, fever, increased erythrocyte sedimentation rate (ESR), low radioactive iodine uptake and a self-limiting clinical course. Recently, however, several authors (Papapetrou and Jackson, 1975; Gluck et al., 1975; Woolf and Daly, 1976; Dorfman et al., 1977; Ginsberg and Walfish, 1977; Amino et al., 1977; Gorman et al., 1978; Inada et al., 1979; Nikolai et al., 1980) have described cases of chronic lymphocytic thyroiditis which showed transient thyrotoxicosis, low radioactive iodine uptake and no thyroidal pain or tenderness, and most of these cases were followed by transient hypothyroidism with spontaneous recovery to a euthyroid state. Such cases have been differentiated from subacute thyroiditis mainly on the basis of histological

Received May 24, 1982 findings, as well as from the absence of thyroidal pain, fever and an elevated ESR. Nevertheless, there are no known predisposing factors in the occurrence of transient thyrotoxicosis in chronic lymphocytic thyroiditis.

In this report, we present a case of chronic lymphocytic thyroiditis associated with rheumatoid arthritis which developed into transient thyrotoxicosis with a low radioactive iodine uptake after cessation of steroid therapy.

\section{Materials and Methods}

Serum thyroxine $\left(\mathrm{T}_{4}\right)$, triiodothyronine $\left(\mathrm{T}_{3}\right)$ and thyroid-stimulating hormone (TSH) were determined by radioimmunoassay, using commercially available kits $\left(\mathrm{Spac} \mathrm{T}_{4}, \mathrm{~T}_{3}\right.$ and TSH kits, respectively; Daiichi Radioisotope Laboratories, Tokyo). The normal ranges of $\mathrm{T}_{4}$ and $\mathrm{T}_{3}$ are 5.0 to $13.5 \mu \mathrm{g} / \mathrm{dl}$ and 90 to $160 \mathrm{ng} / \mathrm{dl}$, respectively. The normal limit for TSH 
values is below $5 \mu \mathrm{u} / \mathrm{ml}$. Serum resin sponge triiodothyronine uptake ( $\mathrm{T}_{3}$ RSU) was measured by a RES-O-MAT $\mathrm{T}_{3}$ kit (Daiichi Radioisotope Laboratories, Tokyo), with normal ranges of 25 to $35 \%$. Circulating thyroid antibodies were examined by the thyroglobulin-coated and the microsome-coated tanned sheep-cell hemagglutination technique, using commercial test kits (Thyroid test and Microsome test, respectively; Fujizoki Pharmaceutical Co. Ltd., Tokyo). An antibody titer of over $1: 100$ is considered to be abnormal with both techniques. Stimulation tests with thyrotropin releasing hormone (TRH) were performed in the patient at fasting and at rest. Two hundred micrograms of TRH were injected into an antecubital vein and venous blood for determination of TSH was taken at $0,30,60$ and 120 minutes. The 24-hour thyroidal uptake of radioactive iodine was measured by the standard technique, with normal values of 10 to $40 \%$. Thyroid scintigraphy was carried out using a scinticamera. Thyroid biopsy was performed by percutaneous aspiration biopsy.

\section{Case Report}

A 51-year-old woman was first seen, as an outpatient, on Nov. 29, 1976, because of reevaluation of hypertension and protei- nuria which had been suggested by an attending physician. In her past history, the patient had been diagnosed as having rheumatoid arthritis about ten years previously and had been treated with dexamethasone at a dose of 0.5 to $1.5 \mathrm{mg} /$ day depending on the severity of the arthritis. Her family history revealed chronic lymphocytic thyroiditis in one of her three daughters, who had also shown postpartum transient thyrotoxicosis after two consecutive deliveries. The patient's blood pressure was $200 / 120 \mathrm{~mm} \mathrm{Hg}$ and on general urinalysis, proteinuria and bacteriuria were noted. She was diagnosed as having essential hypertension and urinary infection associated with rheumatoid arthritis, and was given 2 $\mathrm{mg}$ trichlormethiazide and $2.0 \mathrm{~g}$ nalidixic acid daily. At the same time the dexamethasone was switched to acetylsalicylic acid $(2.0 \mathrm{~g} /$ day $)$ because no findings of arthritis were then observed. Two weeks later she noticed lassitude, nausea and vomiting, suggesting acute adrenal insufficiency, and

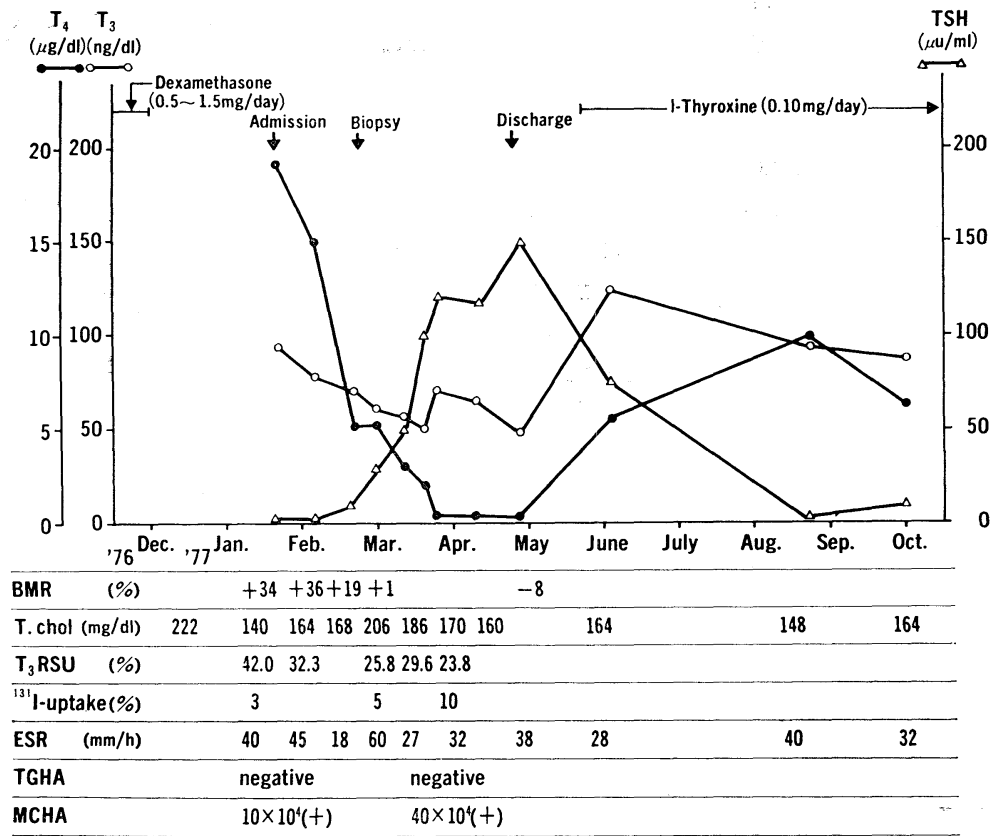

Fig. 1. Changes in thyroid function and erythrocyte sedimentation rate (ESR) in a chronic lymphocytic thyroiditis patient with transient thyrotoxicosis after cessation of steroid therapy. 
was admitted to this hospital on Jan. 20, 1977. She denied any symptoms of upperrespiratory infection or pains in the neck. On physical examination, her height was $158 \mathrm{~cm}$, weight $67.5 \mathrm{~kg}$, blood pressure $172 /$ $92 \mathrm{~mm} \mathrm{Hg}$ and pulse $78 / \mathrm{min}$, regular. Her thyroid gland was not palpable. Finger tremor and exophthalmus were not observed. Pains on motion were noted on the bilateral fingers and knee joints without swelling. The laboratory findings (Fig. 1) included ESR $40 \mathrm{~mm} / \mathrm{h}, \mathrm{T}_{4} 19.4 \mu \mathrm{g} / \mathrm{d} 1$, $\mathrm{T}_{3} 95 \mathrm{ng} / \mathrm{dl}, \mathrm{T}_{3} \mathrm{RSU} 42 \%$, TSH not detectable, ${ }^{131}$ I-uptake $3 \%$ at 24 hours, total cholesterol $140 \mathrm{mg} / \mathrm{dl}$, BMR $+34 \%$, negative reaction for thyroglobulin antibody, antimicrosome antibody titer with $10 \times 10^{4}$, plasma cortisol $6.7 \mu \mathrm{g} / \mathrm{dl}$ at 8:00 am, urinary 17 -hydroxycorticosteroid $3.7 \mathrm{mg} /$ day and 17 oxosteroid $0.8 \mathrm{mg} /$ day, total protein $5.6 \mathrm{~g}$ / dl, $\gamma$-globulin $26.8 \%, I g$ G $2360 \mathrm{mg} / \mathrm{dl}$, Ig A $195 \mathrm{mg} / \mathrm{dl}, \operatorname{Ig} M 90 \mathrm{mg} / \mathrm{dl}$ and $\beta_{1}$ C 85 $\mathrm{mg} / \mathrm{dl}$. THS response to the intravenous injection of $200 \mu \mathrm{g}$ TRH was absent. Pituitary-adrenal function was found to be almost normal in a suppression test by oral administration of $2 \mathrm{mg}$ dexamethasone for two days and a stimulation test by intramuscular injection of $0.5 \mathrm{mg} \mathrm{ACTH-Z}$. Xray findings indicated bone deformity of the bilateral finger joints, compatible with rheumatoid arthritis. Although the RA test was negative, the RAHA test was positive with titer of 40 and antinuclear antibody was positive, showing a diffuse and speckled pattern. At two weeks after admission, a slightly enlarged, symmetrical and nontender struma was noticed with no treatment for the thyroid gland. A percutaneous aspiration biopsy specimen of thyroid gland

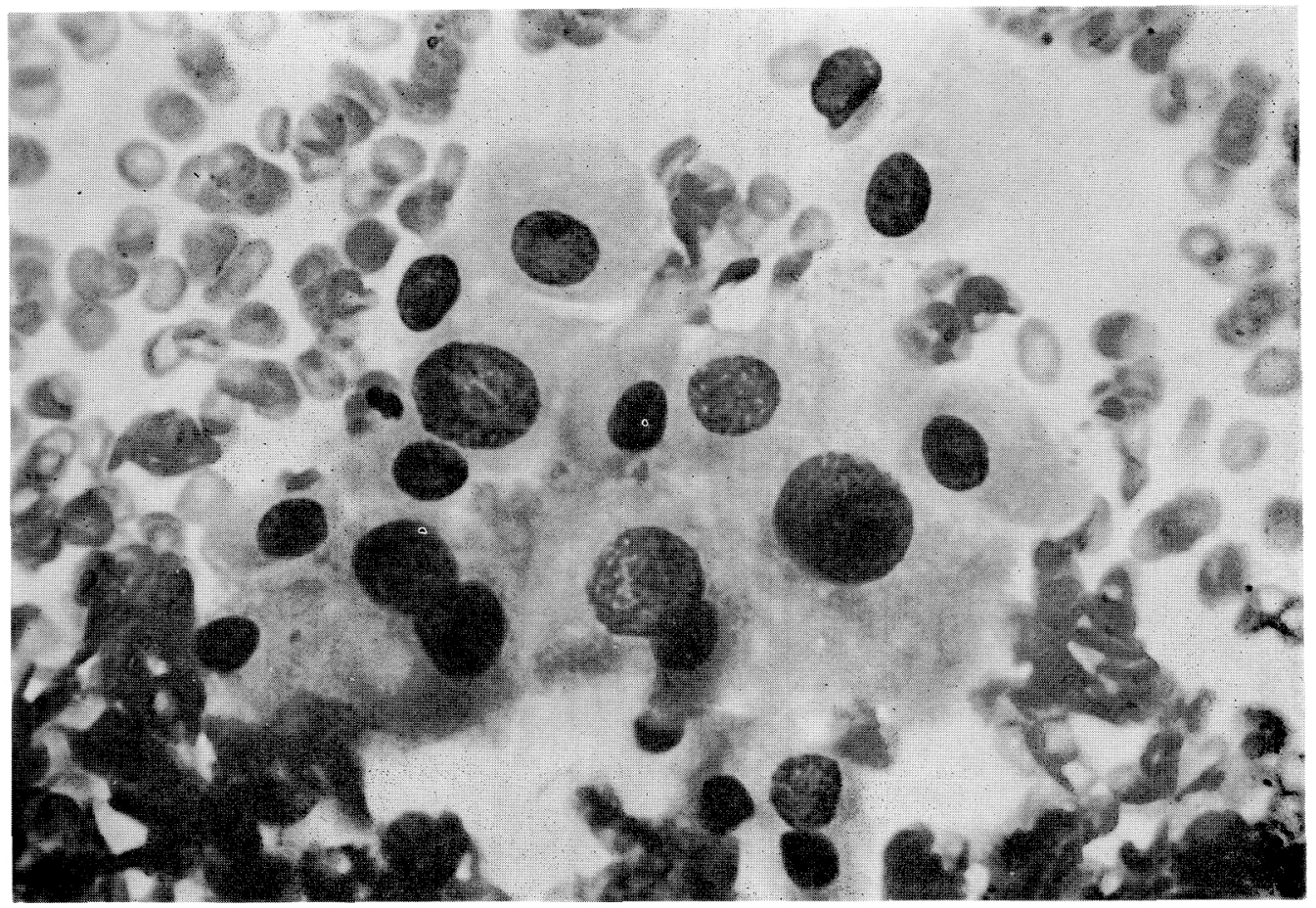

Fig. 2. Biopsy specimen of the thyroid gland, showing moderate lymphocytic infiltration and degeneration of epithelial cells associated with an oxyphilic change in the cytoplasm. This biopsy was undertaken at the time just before the patient developed into a hypothyroid state. 
revealed findings of moderate lymphocytic infiltration and degeneration of epithelial cells associated with a oxyphilic change in the cytoplasm (Fig. 2), compatible with chronic lymphocytic thyroiditis, on Feb. 24, just before she developed into a hypothyroid state. On Mar. 20, $\mathrm{T}_{4}$ decreased to a level of less than $1 \mu \mathrm{g} / \mathrm{dl}$ and $\mathrm{T}_{3}$ level also decreased to $70 \mathrm{ng} / \mathrm{dl}$. Furthermore, the TSH level increased to $120 \mu \mathrm{u} / \mathrm{ml},{ }^{131} I$-uptake increased to $10 \%$ and the antimicrosome antibody titer increased to $40 \times 10^{4}$. A thyroid scintigram showed a slightly enlarged thyroid gland with an irregular patchy concentration of ${ }^{131} \mathrm{I}$. The patient was discharged on Apr. 22, but persistent hypothyroidism continued. Her struma improved after 1-thyroxine replacement therapy at a dose of $0.1 \mathrm{mg} /$ day from May 20 , 1977, and she then maintained a euthyroid state. However, puffy face and nontender, diffuse struma were again noted on June 23, 1978, after she had stopped taking 1thyroxine for six weeks with complaints of palpitations. At that time, $\mathrm{T}_{4}$ and $\mathrm{T}_{3}$ decreased to levels of less than $1.0 \mu \mathrm{g} / \mathrm{dl}$ and $50 \mathrm{ng} / \mathrm{dl}$, respectively, while the TSH level increased to $275 \mu \mathrm{u} / \mathrm{ml}$. Furthermore, the antithyroglobulin antibody titer was $20 \times 10^{3}$ and the antimicrosome antibody titer was $10 \times 10^{4}$. She then maintained a euthyroid state with 1 -thyroxine $(0.15 \mathrm{mg} /$ day) for another one year.

\section{Discussion}

Patients with rheumatoid arthritis show a relatively high incidence of antithyroid antibodies. It has been reported that antithyroglobulin antibodies were found in 24.4\% (Buchanan, 1965) and antimicrosome antibodies were also noted in $18 \%$ (Monterio et al., 1979) of patients with rheumatoid arthritis. On the other hand, Beare (1958) reported that 3 of 33 patients with biopsy-proved Hashimoto's thyroiditis had a history of rheumatoid arthritis. In addition, Becker et al. (1963) found this association in 20 patients (4\%) with probable or definite rheumatoid arthritis in a series of 506 patients with Hashimoto's thyroiditis. However, it is not certain whether these patients with rheumatoid arthritis and Hashimoto's thyroiditis showed typical hypothyroidism or not. Therefore, the true association of these two diseases with hypothyroidism, as seen in the present case, has not commonly been recognized (Monterio et al., 1979). It might be possible to consider that this patient has two separate diseases-rhematoid arthritis as well as chronic lymphocytic thyroiditis with hypothyroidism. However, it is by no means clear whether two different pathological processes could be occurring simultaneously or whether the patient might truly have one disease that has produced manifestations in the thyroid gland as well as other organs.

In this case, the clinical findings of chronic lymphocytic thyroiditis might also have been suppressed by the steroid therapy for rheumatoid arthritis, and acute cessation of the steroid hormone could have caused "destructive" thyroiditis as a form of transient thyrotoxicosis and, at the same time, led to the coexistence of chronic lymphocytic thyroiditis. To our knowledge, no such case has been reported in the literature. It is said that steroid hormone is effective in suppressing the immunological reaction and relieving the clinical signs of chronic lymphocytic thyroiditis. Blizzard et al. (1962) reported that a decrease in the size of goiters, lowering of antithyroid antibody levels, and elevation of protein-bound iodine and butanolextractable iodine to normal values were observed following steroid therapy in three patients with Hashimoto's thyroiditis. However, he also noted that with diminution or cessation of the steroid hormone administration, the goiters and biochemical abnormalities of the disease recurred and the 
patient became clinically hypothyroid. The transient thyrotoxicosis in chronic lymphocytic thyroiditis must be differentiated from factitious thyrotoxicosis, iodine-induced thyrotoxicosis and subacute thyroiditis on the basis of clinical and laboratory findings. The combination of a high serum thyroid hormone concentration and a low radioactive iodine uptake can also be seen with factitious thyrotoxicosis and iodine injection. Moreover, struma is not usually observed in factitious thyrotoxicosis. In the present case, the surreptitious use of thyroid hormone or iodine was denied. The biopsy specimen of the thyroid gland in the patient revealed findings compatible with chronic lymphocytic thyroiditis, without evidence of subacute thyroiditis, at the time just before she developed into an hypothyroid state and, in addition, the ${ }^{131}$ I-uptake was decreased to only $3 \%$, even in the thyrotoxic state. The thyrotoxic state might have resulted from disruption of the thyroid gland by an inflammatory process, with release of thyroid hormone into the circulation. The $T_{3} / T_{4}$ ratio in this patient was relatively low in the thyrotoxic state as indicated by Amino et al. (1978) who reported that this ratio in thyrotoxicosis induced by thyroid destruction $($ ratio $<20(\mathrm{ng} / \mu \mathrm{g})$ ) was lower than that observed in thyrotoxicosis due to Graves's disease. It is conceivable that for any degree of $\mathrm{T}_{4}$ elevation, patients with transient thyrotoxicosis may have less $T_{3}$ than expected in conventional hyperthyroidism because almost all the $T_{3}$ is the result of a peripheral conversion from $\mathrm{T}_{4}$. Recently, it was reported that the histological findings of a patient suffering from chronic lymphocytic thyroiditis with transient thyrotoxicosis improved spontaneously during the course of several months, with spontaneous recovery of the clinical signs and biochemical abnormalities (Inada et al., 1979).

It is known that this kind of transient thyrotoxicosis is often seen during the course of chronic lymphocytic thyroiditis (Papapetrou and Jackson, 1975; Gluck et al., 1975; Woolf and Daly, 1976; Dorfman et al., 1977; Gorman et al., 1978; Inada et al., 1979; Nikolai et al., 1980) or at one to three months after delivery (Ginsberg and Walfish, 1977; Amino et al., 1977 ; Nikolai et al., 1980), and is followed by transient hypothyroidism with eventual recovery to a euthyroid state or, in very rare cases, persistent hypothyroidism. There are reports of four cases of postpartum transient thyrotoxicosis followed by persistent hypothyroidism (Ginsberg and Walfish, 1977; Amino et al., 1977). However, the true predisposing cause of transient thyrotoxicosis during the course of chronic lymphocytic thyroiditis has not yet been clarified. On the other hand, transient thyrotoxicosis after delivery has been suspected to emerge in relation to immunological changes and/or acute changes in steroid hormone concentrations before and after delivery (Nelson and Palmer, 1975; Amino et al., 1976; Amino et al., 1977; Ginsberg and Walfish, 1977). These findings, together with those in the present case, suggest that immunological changes enhanced by a reduction in steroid hormone concentrations might be closely related to the occurrence of transient thyrotoxicosis in chronic lymphocytic thyroiditis, but it remains to be determined what kind of immunologicol changes might play a role in the occurrence of "destructive" thyroiditis. In any case, it should be noted that acute cessation of steroid hormone administration for underlying disease can lead to coexistent chronic lymphocytic thyroiditis as a form of transient thyrotoxicosis. 


\section{Acknowledgements}

We gratefully acknowledge the heloful acives of Dr. Y. Hosoda of the Department of Patholcgy, Keio University School of Medicine and of Dr. R. Ariwa of . the Department of Pathology, Tokyo Metropolitan Okubo Mospital, Japan.

\section{References}

Amino, N., K. Miyai, T. Hashimoto, K. Arai, K. Ishibashi and Y. Kumahara (1976). Transient hyperthyroidism after delivery in autoimmune thyroiditis. J. Clin. Endocrinol. Metab. 42, 296-301.

Amino, N., K. Miyai, R. Kuro, O. Tanizawa, Y. Azukizawa, S. Takai, F. Tanaka, K. Nishi, K. Kuwashima and Y. Kumahara (1977). Transient postpartum hyperthyroidism: Fourteen cases with autoimmune thyroiditis. Ann. Intern. Med. 87, 155-159.

Amino, N., Y. Yabe, K. Miyai, T. Fujie, M. Azukizawa, T. Onishi and Y. Kumahara (1978). Differentiation of thyrotoxicosis induced by thyroid destruction from Graves' disease. Lancet 2, 344346.

Beare, R. L. B. (1958). Iymphadenoid goiter (Hashimoto's disease). Br. Med. J. 1, 480-486.

Becker, K. L., R. H. Ferguson and W. M. McConahey (1963). The connective-tissue diseases and symptoms associated with Hashimoto's thyroiditis. N. Engl. J. Med. 268, 277-280.

Blizzard, R. M., W. Hung, R. M. Chandler, T. Aceto, M. Kyle and T. Winship (1962). Hashimoto's thyroiditis: clinical and laboratory response to prolonged cortisone therapy. N. Engl. J. Med. 267, 1015-1020.
Buchanan, W. W. (1965). The relationship of Hashimoto's thyroiditis to rheumatoid arthritis. Geriatrics 20, 941-948.

Dorfman, S. G., M. T. Cooperman, R. L. Nelson, H. Dupuy, R. L. Peake and R. L. Young (1977). Painless thyroiditis and transient hyperthyroidism without goiter. Ann. Intern. Med. 86, 24-28.

Ginsberg, J. and P. G. Walfish (1977). Post-partum transient thyrotoxicosis with painless thyroiditis. Lancet 1, 1125-1128.

Gluck, F. B., M. L. Nusynowitz and S. Playmate (1975). Chronic lymphocytic thyroiditis, thyrotoxicosis, and low radioactive iodine uptake. $N$. Engl. J. Med. 293, 624-628.

Gorman, C. A., D. S. Duick, L. B. Woolner and H. W. Wahner (1978). Transient hyperthyroidism in patient with lymphocytic thyroiditis. Mayo Clin. Proc. 53, 359-365.

Inada, M., M. Nishizawa, M. Onishi, S. Kurata and H. Imura (1979). Transient thyrotoxicosis associated with painless thyroiditis and low radioactive iodine uptake. Arch. Intern. Med.139, 597599.

Monterio, E., C. Ceboleio and A. Galvac-Teles (1979). Autoantibodies in rheumatic diseases. Lancet 2, 797.

Nelson, J. C. and F. G. Palmer (1975). A remission of goitrous hypothyroidism during pregnancy. J. Clin. Endocrinol. Metab. 40, 383-386.

Nikolai, T. F., J. Brosseau, M. A. Kettrick, R. Roberts and E. Beltaos (1980). Lymphocytic thyroiditis with spontaneously resolving hyperthyroidism (Silent thyroiditis). Arch. Intern. Med. 140, 478-482.

Papapetrou, P. D. and I. M. D. Jackson (1975). Thyrotoxicosis due to silent thyroiditis. Lancet $\mathbf{1}$, 361-363.

Woolf, P. D. and R. Daly (1976). Thyrotoxicosis with painless thyroiditis. Am. J. Med. 60, 73-79. 